\title{
INVESTING IN HEALTH PROFESSIONS EDUCATION: A NATIONAL DEVELOPMENT IMPERATIVE FOR SOUTH AFRICA
}

\author{
D. van Staden \\ School of Health Sciences \\ University of Kwa-Zulu Natal \\ Durban, South Africa \\ e-mail: wallaced@ukzn.ac.za / http://orcid.org/0000-0003-2028-1711
}

\section{ABSTRACT}

Background: Human resources for health are an essential component of any health system. South Africa's National Development Plan identifies the need for a strengthened public health system and improvements in the quality of education and service delivery. While efforts to increase the number of trained health personnel are acknowledged, a lack of sustainable investment in improving the quality of health professions education in South Africa may have detrimental consequences for these national ideals.

Discussion: South Africa's economic growth has declined in recent years, placing pressure on its fiscal capacity and the ability of academic institutions to fund critical aspects relating to training needs within health professions education programmes. Increased intakes at universities have not been supported by concurrent increases in funding required to support evolving training needs. Reduced financial support for health professions education programs has implications for required resource capacity, and will potentially negatively impact the quality, as well as global competitiveness, of health professions training programmes in South Africa. Funding gaps which impact the quality of training also ultimately affect the quality of health services delivered by the health system in the long term.

Conclusion: Political will in support of more sustainable funding mechanisms for ongoing investment into health professions education programs and their evolving training needs is required in order for South Africa to meet its development objectives as outlined in the National Development Plan and its National Health Insurance policy.

Keywords: health professions education, development, health sciences, higher education funding

\section{BACKGROUND}

Human resources for health (HRFH) are an essential component of any health system (Global Health Workforce Alliance 2008) and necessary to deliver effective and efficient health services. Over the last decade, health professions education (HPE) has received notable attention worldwide, with high-income countries having led global initiatives around transformative medical education for health systems strengthening (Frenk et al. 2010). Africa has historically faced a shortage of $\mathrm{HRFH}$, its negative impact on health service delivery being 
linked to the development status of individual countries (WHO 2006), including South Africa which is considered one of the most developed countries on the African continent. This is because the economic performance of countries affects their ability to effectively train, employ and deploy health workers efficiently, with low growth directly impacting on the ability to invest in health (Dovlo 2005). The field of HPE is expected to grow on the continent as the practice of HPE develops in line with more research and capacity development support being provided to the sector (University of KwaZulu Natal 2010).

The World Health Organization (WHO) recognises the importance of health workforce production, having initiated various health workforce strategies over the years. Its Health Workforce Education and Production team

"develops and supports the implementation of policies and strategies that aim to increase the relevance, quality and capacity of health workforce education and training. This includes strengthening institutions and faculties to educate and train a skilled health workforce; promoting investments to improve educational infrastructure; devising mechanisms for improving access to educational materials and technologies; and enhancing national capacities to respond to the health needs of countries through quality education and training, and well-regulated practice." (WHO 2020).

In addition, its policy on Universal Health Coverage (UHC) is contingent upon having a skilled, competent workforce which is fit for purpose and able to meet the health challenges of the $21^{\text {st }}$ century.

The challenges facing health professions education in Africa include, among others, physical infrastructure, accreditation systems, student selection, as well as faculty recruitment, retention, and development (Burdick 2007). Efforts at improving the health system may, however, be impacted by a country's decline in economic growth, which in turn negatively impacts service delivery. In South Africa, the quality of health services has gradually been on the decline. Despite higher levels of spending on service provision, South Africa still has poorer health outcomes than similar developing countries (Moyakhe 2014). There is therefore a need for greater investment in quality health professions education if health service delivery in Africa is to improve.

Over the past decade, the focus on HRFH capacity development in South Africa has largely been around increasing access to training for previously disadvantaged groups, and expanding training opportunities to meet the country's growing health care needs (Mzangwa 2019). This focus has largely been seen through a quantitative lens, with less focus on qualitative aspects relating to training, which include the quality of the teaching and learning and experience, capacity to teach effectively, and adequate resourcing. All of these ultimately impacts the continued competitiveness of health professions training programmes, with 
anecdotal evidence suggesting a progressive decline in government subsidies to higher education institutions, as well as increased strain on institutional budgets.

\section{SOUTH AFRICA'S HEALTH SYSTEM CHALLENGES}

The South African healthcare system still experiences a significant divide in terms of access to, and quality of healthcare services, 25 years post-apartheid (Maphumulo, and Bhengu 2019). In acknowledging its developmental needs and challenges, South Africa embarked on a long-term plan to eliminate poverty and reduce inequality by 2030. The National Development Plan (NDP) (National Planning Commission 2012) identified the need for better educational opportunities, a strengthened public health system, skills development, and improvements in the quality of education and public services. Health is a key priority in South Africa's development plan. However, while approximately 86 per cent of the country's population access health services through the public sector, yet only 50 per cent of the health expenditure is provided by the government (Health Policy Project 2016). Disparities in health spending, and consequently the quality of health care therefore still exist between the public and private sectors, compounding the challenges of access to, and the quality of health services, particularly for people living in rural areas.

South Africa's declining economic growth (Government of South Africa 2020a) has placed increased pressure on the fiscus and academic institutions to manage budgets in the face of rising demands and reduced subsidies. Budget constraints at institutional level are now even more challenging in light of the recent implementation of free higher education for poor and middle-class students in South Africa, against the advice of a Commission set up to explore its feasibility (Heher Commission 2017) and resent demands for remote online learning approaches as a result of the global COVID-19 pandemic. The reality is that underfunding of HPE potentially results in underperformance of health professionals in relation to their required scope of practice and skill levels. While the strategic plan of the National Department of Health identifies improving HRFH by ensuring adequate training and accountabilities as a priority (Department of Health 2014), funding gaps still persist. Political will is therefore needed from the national government and other relevant stakeholders to improve the funding of higher education institutions, so as not to compromise the quality of health professions education and training. The health workforce is the backbone of any health system, and as a key component in implementing health action for sustainable socio-economic development (Anyangwe and Mtonga 2007), sustainable funding mechanisms are required. 


\section{INVESTING IN HPE}

In 2014, Walsh argued that there is not enough investment in health professions education.

In this article, it was noted that at the time, the Lancet Commission estimated the total worldwide spend on the education of healthcare professionals to be approximately $\$ 100$ billion per year, which accounted for less than two percent of health expenditures worldwide. Investments in education are however, investments in health (Barnes et al. 2015). It is worth noting that the majority of the spend on undergraduate education comes from national governments via ministries of education (Walsh 2014). Healthcare and educational institutions therefore have a key role in the development of communities and countries, yet state investment is often inadequate (Oiko Credit 2017).

South African universities are facing challenging economic times, with increased student intakes and insufficient institutional funding to support evolving health professions education training needs. Underfunding can potentially result in the health system not being able to realize its full potential due to the negative impact of underfunding on the skills of its health workers (Dovlo 2005).

Sub-optimal education and training has been cited as a root cause of the African health workforce crisis (Essack 2012). This is because it can result in poor clinical practices and potential negligence that carries the risk of litigation against individual practitioners, employers, and in extreme cases, educational institutions. This risk is even greater in the context of financial pressures on training institutions, which impacts the training quality (Noah 2005). A 2014 report by South Africa's Committee of Health Sciences Deans to the Department of Higher Education and Training indicated that student intakes exceeded university capacity in most institutional programmes. While access for Black students has increased, throughput remains challenging, with high attrition rates and variable quality of undergraduate training noted (Higher Education South Africa 2014). While efforts to increase the number of trained health personnel are commended, simply increasing access to training opportunities, without simultaneously providing the resources to train a competent health workforce, is not enough. Challenges precluding an increased intake were highlighted as inadequate infrastructure (i.e. teaching and learning spaces, skills laboratories and residences, clinical training platforms), shortage of clinical supervisors, such that staff/student ratios recommended by the professional councils cannot be effected, increased operational costs (including travel to off-campus clinical training sites), and a dwindling academic health workforce (Essack 2012).

Several universities in South Africa have been exploring ways to respond to the health needs of the country by partnering with public health facilities in the education and training of health professionals. However, training gaps have been noted (Van Staden 2019); and in order 
to address these, investments in HPE that promote excellence in clinical training standards are required; which will potentially have long-term benefits for the health system as a whole and support efforts towards quality care.

Investments in training HRFH are, however, sometimes constrained by perceptions of the health economy as a consumptive sector, where governments and institutions strive to contain spending, instead of viewing it as contributing to overall socio-economic development of a nation (Cometto and Campbell 2016). This may be a contributing factor to the university sector in South Africa being underfunded (PWC n.d), where government funding has, in real terms, been on the decline in recent years despite the importance of the higher education system as a public good project (PWC n.d). In terms of return for spend therefore, with adequate funding support, we should get competent healthcare professionals who are fit to meet population health needs (Walsh 2014). Anecdotal evidence from various health professions training programmes is that the gradual decline in funding over the past few years has resulted in the inability of institutions to provide adequate resourcing to programmes, which in turn is impacting their ability to provide quality teaching and learning experiences to their undergraduate health science students. The impact of this underfunding negatively affects health professions training programmes which typically require ongoing improvements in clinical training infrastructure as technology improves, requires close monitoring and supervision as part of regulatorycontrolled quality assurance measures, demands travel to clinical training sites and provisions for externships as part of competency development. These all have associated cost implications which are often not factored into planning when universities increase student numbers.

This chronic underfunding of HPE programmes at tertiary level in South Africa, both from the perspective of national support and institutional allocations, is therefore the problem this article hopes to highlight. The argument will proceed in three parts. First it will address the curriculum transformation imperative for South Africa and new dimensions of health professions training programmes that impose additional cost implications, then the need for adequate resourcing to support quality training, and finally health systems strengthening for development.

\section{THE CURRICULUM TRANSFORMATION IMPERATIVE}

Curriculum transformation in health professions education gained global attention after the landmark paper by Frenk et al. (2010) on transforming health professions education in order to strengthen health systems. The paper received much attention in the developed world initially, eventually gaining ground in South Africa a few years later. Frenk et al. purported that the challenges of the $21^{\text {st }}$ century demand a redesign of professional health education that advances 
transformative learning (Frenk et al. 2010). This work was based on the philosophy that an adaptation of competencies to specific contexts is required, which can only be enabled by the mobilization of leadership and enhancements of investments in health education.

The WHO's five-year action plan, Working for Health, also aims to expand and transform the health workforce to accelerate progress towards the goals of Universal Health Coverage, and thereby the improved overall socio-economic development among marginalised countries. The plan calls on countries to view the health and social workforce as an investment rather than a cost, emphasising the need to transform and expand the education and skills of health workers through increased investments (WHO 2018). However, reduced financial support to health professions programmes has a direct impact on the quality of training and subsequently, health service delivery, which potentially negatively impacts the global competitiveness of health professions training programs.

Curriculum transformation in the South African higher education sector has been a focal point recently, spurred by the \#RhodesMustFall movement which centred largely around decolonization of curricula. With institutional attempts at redressing access inequalities for previously disadvantaged groups, many universities adopted a transformation quota system, where in some cases, more than 50 per cent of places in health science programs are allocated to Black students. A significant percentage of these students come from Quintile 1 and 2 schools in rural or semi-rural areas, which are largely under resourced, and experience challenges in delivering a quality education. Many new entrants into health science programs therefore require significantly increased academic support at tertiary level due to a weak basic education foundation from South Africa's public education system (International Monetary Fund 2019).

However, beyond transforming the student profile through improving access and accessibility, there are other elements of transformation in higher education which also require attention. These include the needs for technology-enhanced teaching and learning, specifically highlighted by the recent COVID-19 pandemic, identifying and implementing more effective student support programmes; redesigning assessment systems, providing excellence in quality assurance or programmes, as well as improved focus on student retention and throughput (Mendy and Madiope 2020).

The capacity challenges facing HPE in South Africa have also necessitated a review of training models historically followed by various institutions. The WHO's Working for Health further called for a reform of service models to ensure efficient and effective care, particularly in underserved areas (WHO 2018). This is aligned with the adoption of decentralised models of clinical training now being implemented in the Western Cape and KwaZulu-Natal (KZN) provinces of South Africa, which allows for the clinical training of health science students to 
take place within public health facilities in community settings, rather than academic institutions. In KZN, institutional capacity challenges and an overburdened public health system further emphasized the need for an alternative training model. In 2014, the University of KwaZulu-Natal and the KZN Department of Health entered into a partnership for decentralised clinical training (DCT) to address the notion of fit-for-purpose graduates. These community-based approaches to HPE aspire to produce professionals with locally relevant skills who would be equipped to address community health needs. However, South Africa's health system is itself significantly under-resourced, which underscores this partnership approach towards HPE, with service learning models being a strategy to both address demands within the public health sector, and produce fit-for-purpose graduates. However, even in this context, academic training standards, as stipulated by regulatory authorities, still need to be met.

An important consideration though, is that while the placement of health science students within public health facilities for clinical training purposes will partly relieve some of the demands on academic institutions with larger student numbers, it requires adapted models of clinical teaching and co-supervision with clinicians, in order to be developed and implemented. It may also put a strain on already limited infrastructural and human resources within public health facilities. Therefore even with decentralised clinical training, for transformative HPE initiatives to be successful, addressing the fundamental issues of resourcing, to both attract and retain future health workers to the public sector where the need is greatest, is imperative.

\section{HEALTH SYSTEMS STRENGTHENING}

The health workforce is one of the six building blocks required for strengthening a health system as articulated in the WHO's health systems framework (Figure 1).

Together with financing, leadership and governance, these building blocks all have a direct impact on the quality and safety of healthcare delivered within the health system, as well as the overall goal of improved health for the population. The health workforce is therefore a key component to improved health and improved efficiency within a health system.

The apparent lack of attention to strengthening training in HPE for South Africa is concerning, as this has potential-long term consequences for the health system. As the number of students at universities rises, this must be supported by a concurrent increase in the funding required to sustain quality HPE programs (Wangenge-Ouma 2010).

This article argues that the approach to strengthening the health system in South Africa has been fragmented, with both financing and leadership priorities not supporting the broader training needs of a transformed health workforce, which has implications for the quality of 
Figure 1. The WHO Health Systems Framework ${ }^{1}$

System building blocks

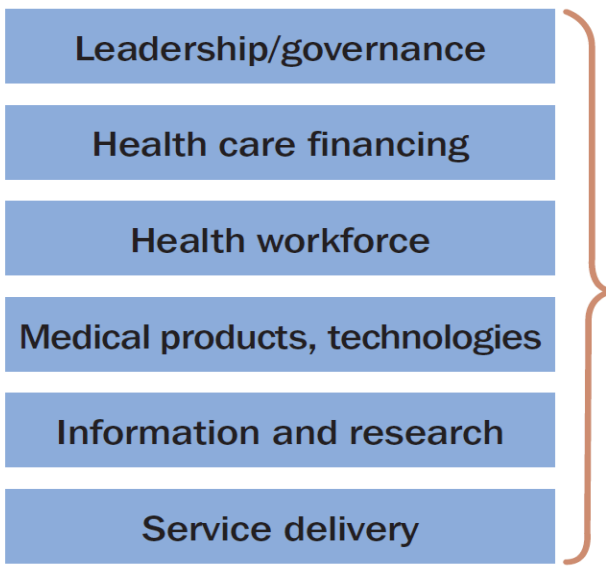

Goals/outcomes

Improved health

(level and equity)

Responsiveness

Financial risk protection

QUALITY

SAFETY

Improved efficiency

Figure 1: WHO's Health System Building Blocks (Batia 2016)

health services. In some cases, institutional reliance on academics to secure third stream income to support their growing training needs is also not sustainable, and defers the responsibility from the government and universities to individual academics. This adds to the pressures on academic and clinical educators, who are already over-stretched in the context of understaffing, under-resourcing, rising academic demands for publication of new knowledge, and $\mathrm{PhD}$ credentialing as a requirement for academic progress. High student-educator ratios also result in reduced contact time between academic or clinical staff and individual students, negatively affecting the quality of the teaching and learning experience. This necessitates an increase in staffing capacity to support evolving training needs. In addition, ageing infrastructure, coupled with high usage and levels of misuse of equipment also negatively impacts the quality when training larger numbers of students (Dovlo 2003). The resultant environment is therefore not conducive to grooming future generations of well-trained health professionals who are expected to become the change agents the health system needs, as the inverse relationship between redress efforts and funding allocations directly impacts the quality of training.

Shay (2017) further argued that if South Africa's Higher Education system continues to expand without concomitant investment in teaching and learning, it will not achieve its policy goals of equity of access and outcomes. Similarly, South Africa will also not achieve the WHO's Health Workforce Education and Production goals around improved relevance, quality and capacity of health professions training programmes to produce adequately skilled practitioners who can build the health system. A further consideration is that in order to be 
globally aligned, and for our health professions graduates to remain relevant and competitive in an increasingly interconnected world, South Africa has to take cognizance of the inputs required to achieve these ideals (Figure 2).

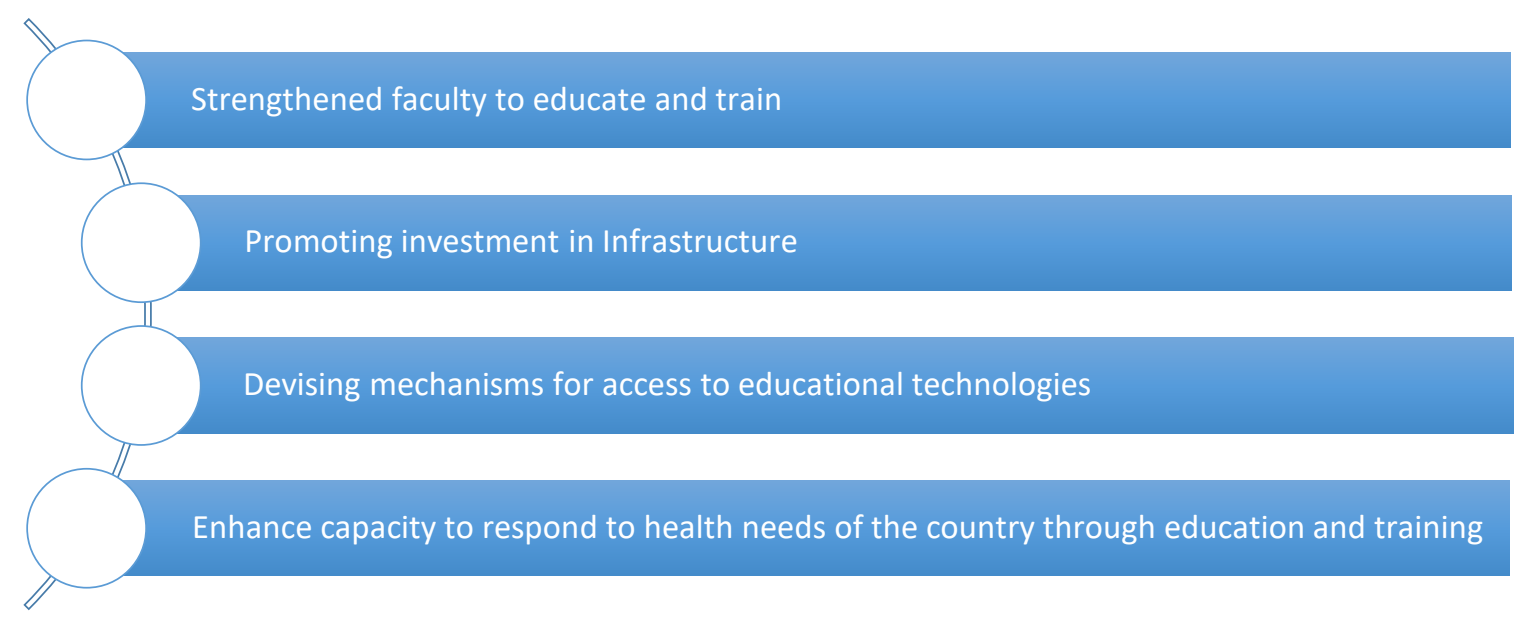

Figure 2: Health Workforce Education and Production Strategies (WHO 2020)

Efforts to educate and train faculty in line with transformation goals have also been necessary, in addition, devising mechanisms for access to educational technologies in line with blended learning; a need made apparent as a result of the COVID-19 lockdown and distance learning imperatives, adds more pressure to the strained budgets of institutions. HPE programmes are also expected to respond to the health needs of the country through their education and training initiatives. Therefore, the one gap that remains unaddressed, at least not in a sustainable way when looking at the WHO's Health Workforce Education and Training Strategies (Figure 1), is investment in infrastructure. These infrastructure investments will facilitate better quality education (Burdick 2007).

It is clear that South African health professions training programmes need undergraduate curricula that are fit for purpose (Shay 2017). In line with this, South Africa adopted a comprehensive competency framework in the training of health professionals, based on the CanMEDs model (South African Qualifications Authority 2012), local training now needs to be more holistic, with increased emphasis on the development of communication, leadership and health advocacy skills amongst others, in teaching and learning programs (Figure 1). This supports a developmental approach to the training of health care professionals. In addition, new and ongoing investments in staff development, teaching capacity and learning innovations and technologies (Dovlo 2003) will have to be accommodated in order to develop these competencies. 


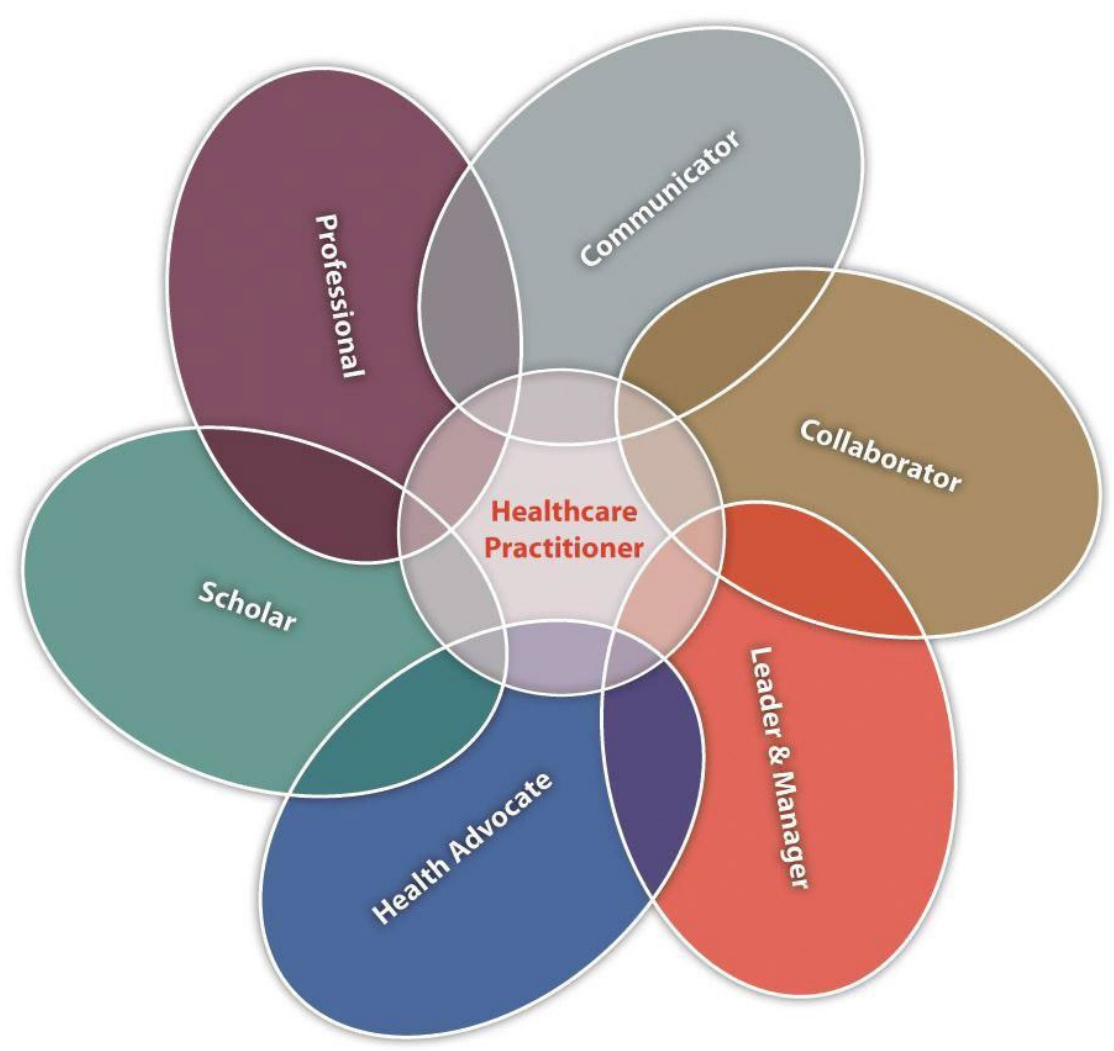

Figure 3: Core competencies for undergraduate students in clinical associate, dentistry and medical teaching and learning programs in South Africa (South African Qualifications Authority 2012)

Faculty will further need be trained on how to implement these competencies within training programmes. If these growing needs within HPE programmes in South Africa are not addressed, they could potentially result in high levels of frustration and burn-out among academic staff and result in underperformance of both students and educators.

It is not surprising that the Global Health Workforce Alliance recognises the value and benefits of a competent and motivated health workforce in building stronger health systems and improved health outcomes (Global Health Workforce Alliance 2008). Therefore, the value of a motivated health workforce in achieving national health and development objectives, which begins at the level of training, should not be underestimated (WHO 2006). It is therefore apparent that simply increasing the number of trained health professionals in South Africa will not provide a quality, sustainable solution to the current and future needs of South Africa's health care system. Training needs must be addressed, which demands holistically investing in the development and support of a competent health workforce who can deliver quality health services effectively, particularly in underserved areas (Essack 2012). 


\section{INVESTING IN HPE: A DEVELOPMENT IMPERATIVE}

The development of HRFH in South Africa is a complex developmental matter. Declining funding allocations for HPE programmes will only serve to worsen the current reality at institutional level. Educational improvements, however, have the potential to address issues of poverty and underdevelopment where supported by adequate funding for training, as well as enhancing the productivity of the health workforce (West 2012). As such, investing in HRFH has the potential to contribute to broader development outcomes (Cometto, and Campbell 2016), and is an imperative for low- and middle-income countries, such as South Africa, that want to improve the quality of health services.

A more comprehensive funding approach is therefore required in order to align the national strategy for increased capacity in HPE to the ideals of the country's National Development Plan, with a greater focus on qualitative issues that have an impact on training. Institutional co-founding support and increased subsidization from the fiscus is necessary, and should include funding for additional staffing, investment in teaching and learning resources, equipment upgrades and improving infrastructural capacity. With South Africa soon embarking on the implementation of a National Health Insurance (McIntyre, and Ataguba 2014), the need to train health professionals who can function optimally within this new system is increasingly imperative. Furthermore, addressing inefficiencies affecting healthcare workers at every stage of their professional lives, including in their training, is essential (WHO 2006).

Building the health workforce of the future and improving the quality of HPE and health services in South Africa requires significant investment (Global Forum on Human Resources for Health 2017) if HPE is to be transformed in line with national development objectives (Figure 4). Investment in health and health professions' education not only improves the health of a population, but also yields substantial economic gains and contributes to a nation's development (PAHO n.d.). McGregor et al. (2020) argue that when considering the cost of HPE in South Africa, it is an excellent investment. Therefore, decisive leadership and political will, both at national and institutional levels, around improving funding mechanisms for higher education in general, and HPE in particular, are needed. This will have long-term benefits for a comprehensive, quality and universal health service (Ayo-Yusuf 2015) within a framework of social accountability in the training of health professionals for the South Africa context (Van Heerden 2013).

While the duty of health professionals is to deliver quality clinical care, the responsibility for such an approach begins at the level of training, where appropriate principles can be taught, modelled and reinforced for future clinical practice. It is encouraging to note that South Africa's Ministry of Higher Education has recently acknowledged the need for increased funding in 
higher education in general, and has committed to additional funding towards the infrastructure and teaching resources of the Post-School Education and Training (PSET) sector (Government of South Africa 2020b). This is necessary so that individuals and institutions that bear the costs of health professions education get the best possible outcomes (Walsh 2014).

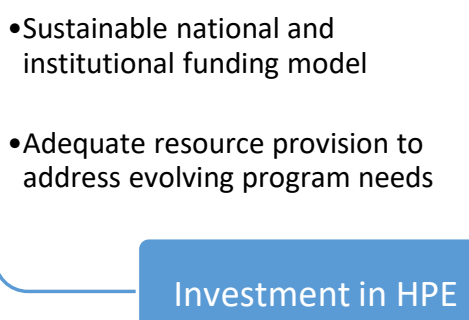

\section{Quality of Graduates}

-Improvement in quality of training

- Higher levels of throughput

-Inclusion of non-clinical

competencies in training
- Better quality of services

-Improved efficiency within the health system

- Better health outcomes

Improved health service provision

Figure 4: Programmatic funding has implications for health service provision

A case is therefore made for investment in health professions education, regardless of the state of the economy in individual countries (Walsh 2014). Cost analyses in medical education should not be used as a means of cutting back on spending, but rather for making the case for increased investment.

The evolving needs in health profession education and training demands its own strategic plan if South Africa is to meet its developmental objectives. In the absence of adequate investment into HPE and HRFH, building competitive health programs that attract the best local and international students, as well as drive the achievement of quality health services in South Africa, may be nothing short of a noble ideal. Therefore, government and institutions must work together to identify comprehensive, sustainable funding mechanisms that support the delivery of quality HPE programs, both within universities and at decentralised training sites within the public health sector, to align with emerging models of training towards a broader health system strengthening and national development agenda for South Africa.

The investments required will necessitate additional financial resources. If these are made available, the returns for societies and economies can be measured in terms of improved health outcomes for millions of people, creation of qualified employment opportunities and enhanced global health security. The case for investing in health professions education, jobs and 
leadership is therefore clear; and relevant stakeholders must commit to action (WHO 2020).

\section{CONCLUSION}

South Africa has progressive plans to address health service delivery and improve the quality of health services nationally. However, there are fundamentals that must be addressed at the level of higher education and training when it comes to investments in health professions education and training, in order for these efforts to be sustainable.

This article highlighted the need for greater emphasis on sustainable investment in HPE within South Africa. It argued that factors which support quality training have cost implications, and must be routinely reviewed in line with evolving health care practice and health system needs. The historical focus on numbers in line with transformation objectives, without associated funding to support transformation in health professions education is potentially detrimental to the goals of health system strengthening and the implementation of NHI in South Africa.

National leadership and other higher education stakeholders therefore need to be cognizant of the imperative to maintain quality education and training to support a strengthened health system. Evolving needs in the clinical education of health professionals should be regularly evaluated and supported by improved infrastructure and resource requirements, where necessary. Committed leadership and the political will to invest in HPE, even within a tough economic climate, is therefore essential for strengthening South Africa's health system in the long term.

\section{REFERENCES}

Anyangwe, S., and C. Mtonga. 2007. "Inequities in the Global Health Workforce: The Greatest Impediment to Health in Sub-Saharan Africa." International Journal of Environmental Research and Public Health 4(2) (June): 93-100.

Ayo-Yusuf, L. 2015. South Africa needs a new way to address the doctor shortage. Online: The Conversation. http://theconversation.com/south-africa-needs-a-new-way-to-address-the-doctorshortage-41136.

Batia, T. 2016. "A 'health system' perspective on scaling up hospital cataract services." Community Eye Health 28(91): 56.

Barnes, A. J., R. S. Bono, A. D. Kimmel and S. H. Woolf. 2015. Investments in Education are investments in health: The State Perspective. Virginia Commonwealth University. https://societyhealth. cu.edu/media/society-health/pdf/EHI4StateBrief.pdf.

Burdick, William. 2007. "Challenges and issues in health professions education in Africa." Medical Teacher 29(9) (November): 882-886.

Cometto, G., and J. Campbell. 2016. "Investing in human resources for health: Beyond health outcomes." Human Resources for Health 14(51). https://doi.org/10.1186/s12960-016-0147-2.

Department of Health. 2014. Strategic Plan 2014/5-2018/9. Pretoria: National Department of Health. 
Dovlo, D. 2003. The Brain Drain and Retention of Health Professionals in Africa. A case study prepared for a Regional Training Conference on Improving Tertiary Education in Sub-Saharan Africa: Things That Work. Accra. https://www.researchgate.net/profile/Delanyo_Dovlo/publication/ 265108883_The_Brain_Drain_and_Retention_of_Health_Professionals_in_Africa_The_Brain Drain_and_Retention_of_Health_Professionals_in_Africa/links/565d807108ae1ef929829a7e/ The-Brain-Drain-and-Retention-of-Health-Professionals-in-Africa-The-Brain-Drain-andRetention-of-Health-Professionals-in-Africa.pdf.

Dovlo, D. 2005. "Wastage in the health workforce: Some perspectives from African countries." Human Resources for Health 3(6). https://doi.org/10.1186/1478-4491-3-6.

Essack, S. 2012. "Models for increasing the health workforce." The South African Medical Journal 102(11) (September): 830-832.

Frenk, Julio., Lincoln Chen, Zulfiqar A. Bhutta, Jordan Cohen, Nigel Crisp, Timothy Evans, Harvey Fineberg, et al. 2010. "Health professionals for a new century: Transforming education to strengthen health systems in an interdependent world." The Lancet 376(9756): 1923-1958.

Global Forum on Human Resources for Health. 2017. Dublin Declaration on Human Resources for Health: Building the Health Workforce of the Future. Dublin: Global Forum on Human Resources for Health.

Global Health Workforce Alliance. 2008. Scaling up, Saving Lives. Douala: World Health Organisation. https://www.who.int/workforcealliance/documents/Global_Health\%20FINAL\%20REPORT.pdf.

Government of South Africa. 2020a. Budget review 2020. Pretoria: National Treasury. http://www.treasury.gov.za/documents/national\%20budget/2020/review/FullBR.pdf (Accessed 10 December 2020).

Government of South Africa. 2020b. South Africa: Big Investment in Higher Education Infrastructure. https://allafrica.com/stories/202007230658.html.

Health Policy Project. 2016. Health Financing Profile: South Africa. Washington, D.C.: USAID.

Heher Commission. 2017. Commission of Inquiry into Higher Education and Training. Pretoria: Department of Justice.

Higher Education South Africa. 2014. Higher education challenges. Cape Town: Higher Education South Africa.

International Monetary Fund. 2019. Struggling to make the grade: A review of the causes and consequences of the weak outcomes of South Africa's Education System. South Africa: International Monetary Fund.

Maphumulo W. T. and B. R. Bhengu. 2019. "Challenges of quality improvement in the healthcare of South Africa post-apartheid: A critical review." Curationis 42(1) (May): 1901.

McGregor, R. G., G. Zihindula, L. Chola, and A. J. Ross. 2020. "The training of healthcare professionals: An expense or an investment?" South African Medical Journal 110(5) (April): 369373.

McIntyre, D., and J. Ataguba. 2014. Access to quality health care in South Africa: Is the health sector contributing to addressing the inequality challenge? Cape Town: UKAid.

Moyakhe, N. P. 2014. "Quality healthcare: An attainable goal for all South Africans?" The South African Journal of Bioethics and Law 7(2) (November): 80-83.

Mzangwa, S. T. 2019. "The effects of higher education policy on post-apartheid South Africa." Cogent Education 6(1). DOI: 10.1080/2331186X.2019.1592737.

National Planning Commission. 2012. National Devlopment Plan 2030: Our Future - Make it Work. Pretoria: National Planning Commission.

Noah, L. 2005. "Medical Education and Malpractice: What's the Connection?" Health Matrix Clevel 15(1): 149-163.

Oiko Credit. 2017. Investing in Healthcare and Education. https://www.oikocredit.coop/ $\mathrm{k} / \mathrm{en} / \mathrm{n} 171 /$ news/view/177499/235625/investing-in-healthcare-and-education.html. 
PAHO see Pan American Health Organisation.

Pan American Health Organisation. n.d. Universal Health: Health Professions Education Transformation. https://www.paho.org/hq/index.php?option=com_content\&view=article\&id= 13000:health-professions-education-transformation\&Itemid=39594\&lang=fr.

PWC. n.d. Funding of public higher education institutions in South Africa. Online https:/www.pwc.co.za/en/publications/funding-public-higher-education-institutions-sa.html (Accessed 22 February 2021).

Shay, Suellen. 2017. "Educational Investment towards the ideal future: South Africa's strategic choices." South African Journal of Science 113(1/2). http://dx.doi.org/10.17159/sajs. 2017/20160227.

South African Qualifications Authority. 2012. Core Competencies for Undergraduate Students in the Clinical Associate, Dentistry and Medical Teaching and Learning programmes in South Africa. Pretoria: South African Qualifications Authority.

University of KwaZulu Natal. 2010. Medical Education Partnership Initiative. http://mepi.ukzn.ac.za/ Homepage.aspx.

Van Heerden, B. 2013. "Effectively addressing the health needs of South Africa's population: The role of health professions education in the 21st century." South African Medical Journal 103(1): 21+.

Van Staden, D. B. 2019. "Decentralised Clinical Training in Optometry: A developmental strategy for eye health in KwaZulu-Natal?" Primary Healthcare Research and Development 20: E35. doi:10.1017/S1463423618000397.

Walsh, K. 2014. "Medical Education: The case for Investment." African Health Sciences 14(2) (June): $472-474$.

Wangenge-Ouma, G. 2010. "Funding and the attainment of transformation goals in South Africa's higher education." Oxford Review of Education 36(4): 481-497.

West, M. 2012. Education and Global Competitiveness. In Rethinking Competitiveness, ed. K Hasset. Washington, DC: American Enterprise Institute Press.

WHO see World Health Organization.

World Health Organization. 2006. The World Health Report 2006 - Working together for health. Geneva: World Health Organization.

World Health Organization. 2018. Health Workforce. February 13. http://www.who.int/ $\mathrm{hrh} /$ news/2017/working4health_fiveyearactionplan/en/.

World Health Organization. 2020. State of the World's Nursing 2020: Investing in education, jobs and leadership. Geneva. World Health Organization. 